\title{
Impacts of climate change on agricultural production in Nepal: Case of Kavre and Jumla districts
}

\author{
KS Pandey ${ }^{1^{*}}, \mathrm{H}_{\text {Shrestha }}{ }^{1}$, LP Devkota ${ }^{2}$ \\ ${ }^{1}$ Central Department of Environment Science, Tribhuvan University, Kathmandu \\ ${ }^{2}$ Central Department of Hydrology ad Meteorology, Tribhuvan University, Kathmandu
}

\begin{abstract}
The study the analyzed relationship of climate change with agricultural production in Kavre and Jumla districts. The specific objective of the study was to find out the dimension and linkage between agricultural production and climatic parameters in Kavre and Jumla. Time series data were analysed for the study. The data was sourced from the Department of Hydrology Meteorology, Department of Agriculture, and National Bureau of Statistics. Descriptive statistics, linear analysis test and back ward difference filter were the analytical tools used to determine the impact of climate change on productivity. During harvest period, the correlation of rice yield with temperature and rainfall was negative at Kavre but positive at Jumla. Similarly, the correlation of wheat yield with temperature and rainfall was positive at Kavre but negative at Jumla. The result showed that extreme fluctuation in weather caused negative impact on production in Jumla in compared to Kavre districts.
\end{abstract}

Key words: Agriculture, Jumla, Kavre, Production

\section{Introduction}

Climate change will profoundly affect the agriculture with bigger impact in developing countries (Ster n, 2006). According to Intergovernmental Panel on Climate Change (IPCC) average annual temperature could rise by $2^{\circ} \mathrm{C}$ overland in most of South Asia by mid- 21st Century. The frequency of hot days in Asia is likely to increase (IPCC, 2014). More rainfall and high rainfall days are projected over parts of South Asia (IPCC, 2014). Even at relatively low level of warming of 1 to $2^{\circ} \mathrm{C}$, food productivity could be negatively impacted. However, cooler regions are likely to benefit from warmer temperatures leading to an increase the arable land (IPCC, 2014). Rice is most vulnerable in Norther $\mathrm{n}$ part of South Asia, but changes in climate may boost wheat production in parts where war mer temperature make it possible to grow two crops per year in mountainous region (IPCC, 2014).

Agriculture in Nepal is more vulnerable to climate change because $64 \%$ of the cultivated land is rain-fed and two third of the population has agriculture based livelihood (F AO, 2004; NAPA, 2010; MoE, 2011). Agriculture sector in Nepal is oriented mainly toward subsistence with rice, wheat and maize (Regmi \& Adhikari, 2007). Over the past few years,

*Corresponding author, email address: ukeertisp2010@gmail.com the delay in monsoon season experienced in Nepal has changed the cropping patter $n$ and crop maturity period (Regmi \& Adhikari, 2007). It has delayed the planting and harvesting season by a month, which in tur $n$ has affected rotation practices. The delay in monsoon season has also made thousands of hectares of farm land fallow and reduced production due to lack of water (Regmi \& Adhikari, 2007). Every crop has a temperature range for their vegetative and reproductive growth. When temperature falls below the range or exceeded the upper limit then crop production faces constraints. Some studies have been conducted for evaluating the potential effects of climate change on agriculture in global level (Kane et al., 1992; Rosenzweig \& Parry, 1994; Darwin et al., 1995), regional level (Adams et al., 1990, 1993) and farm level (Kaiser et al., 1993; Easterling et al., 1993). Some others are conducted in the effects of climate change on crop yields (Dixon et al., 1994; Kaufmann \& Snell, 1997).Maximum temperature is more vulnerable and has negative impact on the rice yield compared to minimum temperature. Combined effects are more significant compared to their individual effect on the rice production (Basak et al., 2010). Study done on CO ${ }_{2}$ enrichment technology at Khumaltar revealed that the yield of rice and wheat increased by $26.6 \%$ and $18.4 \%$ due to double $\mathrm{CO}_{2}$, 
$17.1 \%$ and $8.6 \%$ due to increase in temperature respectively. Increase in maximum temperature during ripening phase contribute to an increase in rice yield up to a critical threshdd of $29.9^{\circ}$ a1C, but the rice yield declines when the temperature goes beyond this threshold (Karn, 2014). A crop simulation model (DSSAT) to study the effects of $\mathrm{CO}_{2}$, temperature and rain in NARC showed positive effect in yield of rice and wheat in all regions. Other important factor is water stress, which has adversely affected the production of rice, maize and wheat in many parts of Asia (T ao et al., 2004). The present study attempted to determine the impacts of climate variability on rice and wheat. The study focused on the correlation analysis of rice and wheat with maximum and minimum temperature and rainfall.

\section{Materials and Methods Study area}

The study area is Kavre and Jumla districts (fig. 1) of Nepal. Kavre is predominantly $r$ ural with an average population density of about 327 persons per square kilometer . The district belongs to one of the densely populated among hill districts of Nepal. The main part of the district lies in the hills and mountain between Mahabharat and Lesser Himalaya leading to agro-climatic variations in different pockets of the district. The climate is sub-tropical in the middle mountain and cool temperate in the high mountain region (District profile of Kavre, 2001). Jumla is one of the mountainous districts of Mid-western development region of Nepal. Out of the total area of 2, 54,365 ha, the cultivated land is 39,468 ha and rice is grown in 3,009 ha (Sapkota et al, 2010). Jumla is a unique place in Nepal, where rice is cultivated in the highest altitude in the world (Paudel \& Thakur, 2009). The temperate and sub-temperate type of climate prevails in this district. Sub-polar type of climate is also found on small part of this district (District profile of Jumla, 2001).

\section{Method of data collection and analysis}

For the trend analysis of temperature and precipitation, monthly average temperature (maximum and minimum) and precipitation from 1990 to 2013 of Panchkhal and Jumla stations were sourced from Department of Hydrology and Meteorology (DHM). The annual cereal yields of Kavre and Jumla District from 1990-2013 were sourced from Ministry of Agriculture (MoA). The obtained data were thoroughly checked and screened. The trends of temporal and spatial variations of rainfall and temperature were analysed using linear regression. A time series analysis was done to understand the past rainfall pattem to help future projections and planning using the past and present data.

The average monthly data of certain years were missing. The data were fulfilled by Arithmetic Average Method and linear trend method. Mean rainfall and mean temperature was computed to find out the mean characteristics and the variability of the data. The computations were done over both the spatial and temporal domains. For the study purpose mean, standard deviation and coefficient of variation were computed for rainfall analysis whereas only mean and standard deviation were computed for temperature analysis. Backward difference filter was used to de-trend the non stationary time series. The correlation between annual cereal yield and a climate variation was determined.
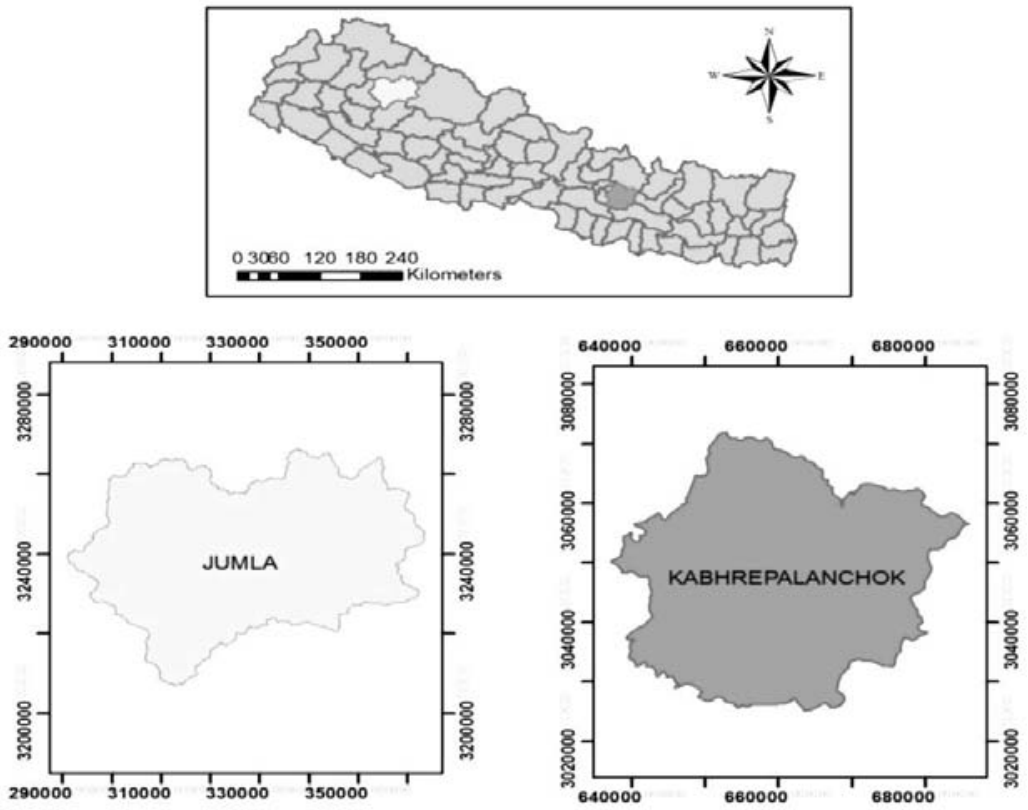

Fig.1 District map of Jumla and Kavre 


\section{Backward differential filter}

Agricultural production, area, productivity and total output are all influenced by a large number of nature-determined factors. There are generally year to year variation in the area, productivity and production as the results of weather or inputs or combination of all associated factors. Hence, it is difficult to isolate the factors responsible for the crop production. While, the technological factors increase the yields gradually over the time, weather variability alone may be the factor that has strong influence on year to year yield changes. Occurrences of extreme weather conditions like, floods, droughts, heat or cold waves, flash floods, hail stoms, etc. all are hazardous for the field crops. Moreover, subtle fluctuations in weather variables during the critical phases of crop growth can also have significant impact on the yields. The year-wise changes in agricultural plantation area have been taken care by considering yield rather than the production. However, influences of technological advancement, such as better seeds, application of pesticides and fertilizer, mechanization of agricultural practices, etc. are believed to be tak en care by applying the backward differential filter. This is one of the widely used methods for de-training the non-stationary time series. This method consists of taking the difference between the value in one year and the value in the previous year, which reduces piecewise linear trends to small constant terms. This filter has been used to isolate inter-annual fluctuations to remove the low frequency variations of any time series.

\section{Results and Discussion}

Trends of Key Climatic Variables of Kavre and Jumla A general increasing trend in temperature has been found over Nepal. The maximum temperature was found to be increasing at a higher rate $\left(0.05^{\circ} \mathrm{C} /\right.$ year $)$ than the minimum temperature $\left(0.03^{\circ} \mathrm{C} /\right.$ year $)$ (Practical action, 2009). The present study is also consistent with existing trend in the country. The rate of increase in average temperature is higher in the Jumla $\left(0.54^{\circ} \mathrm{C}\right)$ than in $\mathrm{K}$ avre $\left(0.03^{\circ} \mathrm{C}\right)$. The average annual maximum temperature for Kavre and Jumla were respectively $28.41^{\circ} \mathrm{C}$ and $20.99^{\circ} \mathrm{C}$. The average minimum temperature for Kavre and Jumla were respectively $14.04^{\circ} \mathrm{C}$ and $4.91^{\circ} \mathrm{C}$. The maximum temperatures showed increasing trends in both Jumla and Kavre, while minimum temperature had increasing trend in Jumla, but decreasing in Kavre. Likewise, the rainfall trend was increasing in Jumla while decreasing in Kavre (Table 1).
Change in the annual rainfall cycle, intense rainfall and longer droughts have been observed in the country. The number of days with $100 \mathrm{~mm}$ of heavy rainfall is increasing. The timing and duration of rainfall is changing (Climate Change Policy, 2011). The mean annual precipitation in Kavre was $1121.13 \mathrm{~mm}$ and in Jumla $806.24 \mathrm{~mm}$ (Table 1). There was variability in the pattern of precipitation from 1990 to 2013 and decreasing trend was obser ved in $\mathrm{K}$ avre, but no significant trend was observed in Jumla.

\section{Relation of rice and wheat production with variability of temperature and rainfall}

At Kavre and Jumla district, growing season (har vesting period) of rice is September-October and growing season of wheat for Kavre is March-April-May and for Jumla is MayJune. The P earson cor relation was analysed between maximum and minimum temperature with rice and wheat yield at both Kavre and Jumla. The analysis was carried out for the period of the plantation, maturity and harvest (Fig. 2, 3, 4, 5; Table 2, 3). There is always a threshold temperature requirement for a particular crop for its optimum growth. An increase in temperature up to $4^{\circ} \mathrm{C}$ and rainfall up to $20 \%$ could increase yield from 0.09 to $7.5 \%$ (Nayaju et al., 2004). However, temperature could be detrimental, if it exceeds these limits. Photosynthesis slows down as the thermometer rises, which also slows the plant's growth and capacity to reproduce. The impact is assessed for each crop based on the cropping periods of respective crop.

Rice yield has been fluctuating along with the fluctuation of temperature. The optimum temperature of $30^{\circ} \mathrm{C}$ during day time and $20^{\circ} \mathrm{C}$ during night time seems to be more favorable for development and growth of rice (Sapkota et al., 2010). However, the productivity declines, when the day temperature goes beyond $29.9^{\circ} \mathrm{C}$ (Karn, 2014).

The analysis of rice and maximum temperature during transplant stage (Fig. 2) showed positive correlation at both the districts. At Kavre, minimum temperature showed positive correlation with rice transplant period, but negative correlation with both maturity and harvest period (Fig. 2a, 2b). At Jumla (Fig. 2c, 2d), maximum temperature showed negative cor relation with rice maturity period i.e., with increase in maximum temperature, there will be decrease in net yield. The transplant period showed negative

Table 1: Temperature and rainfall trends of the study areas

\begin{tabular}{|c|c|c|c|c|c|c|c|}
\hline \multirow[b]{2}{*}{ Mean } & \multicolumn{4}{|c|}{ Temperature $\left({ }^{\circ} \mathrm{C} / \mathrm{yr}\right)$} & \multicolumn{3}{|c|}{ Rainfall (mm) } \\
\hline & Kavre & Trend & Jumla & Trend & Average & Kavre & Jumla \\
\hline Maximum & 28.41 & 0.033 & 20.99 & 0.546 & Annual & 1121.13 & 806.24 \\
\hline Minimum & 14.04 & -0.019 & 4.91 & 0.067 & Trend & -11.26 & -0.010 \\
\hline
\end{tabular}


correlation, whereas maturity and harvest period showed positive correlation with minimum temperature. Increase in maximum and minimum temperature has been found to reduce the yield at $\mathrm{K}$ avre, but the increase in minimum temperature is favorable at Jumla.

The analysis of rice and total rainfall (Fig. 2a) during both transplant and harvest period showed negative correlation at Kavre i.e. yield did not depend upon rainfall. At Jumla, both maturity and harvest period showed positive correlation which meant rice yield depended upon rainfall (Fig. 2b).

In case of wheat yield at $\mathrm{K}$ avre (Fig. $4 \mathrm{a}, 4 \mathrm{~b}$ ), maximum temperature showed positive cor relation and minimum temperature showed negative correlation for plantation and maturity period. However, maximum temperature showed negative correlation and minimum temperature showed positive correlation for the harvest period. At Jumla (Fig 4c, 4d) plantation period showed negative correlation with both maximum and minimum temperature. But, both maturity and har vest period showed positive cor relation with maximum and negative with minimum temperature.

The analysis of wheat and total rainfall ( $\mathrm{F}$ ig. 5a) during plantation and maturity period showed negative correlation at K avre. However, har vest period showed positive correlation. At Jumla (Fig. 5b) plantation and harvest period showed positive correlation with rainfall.

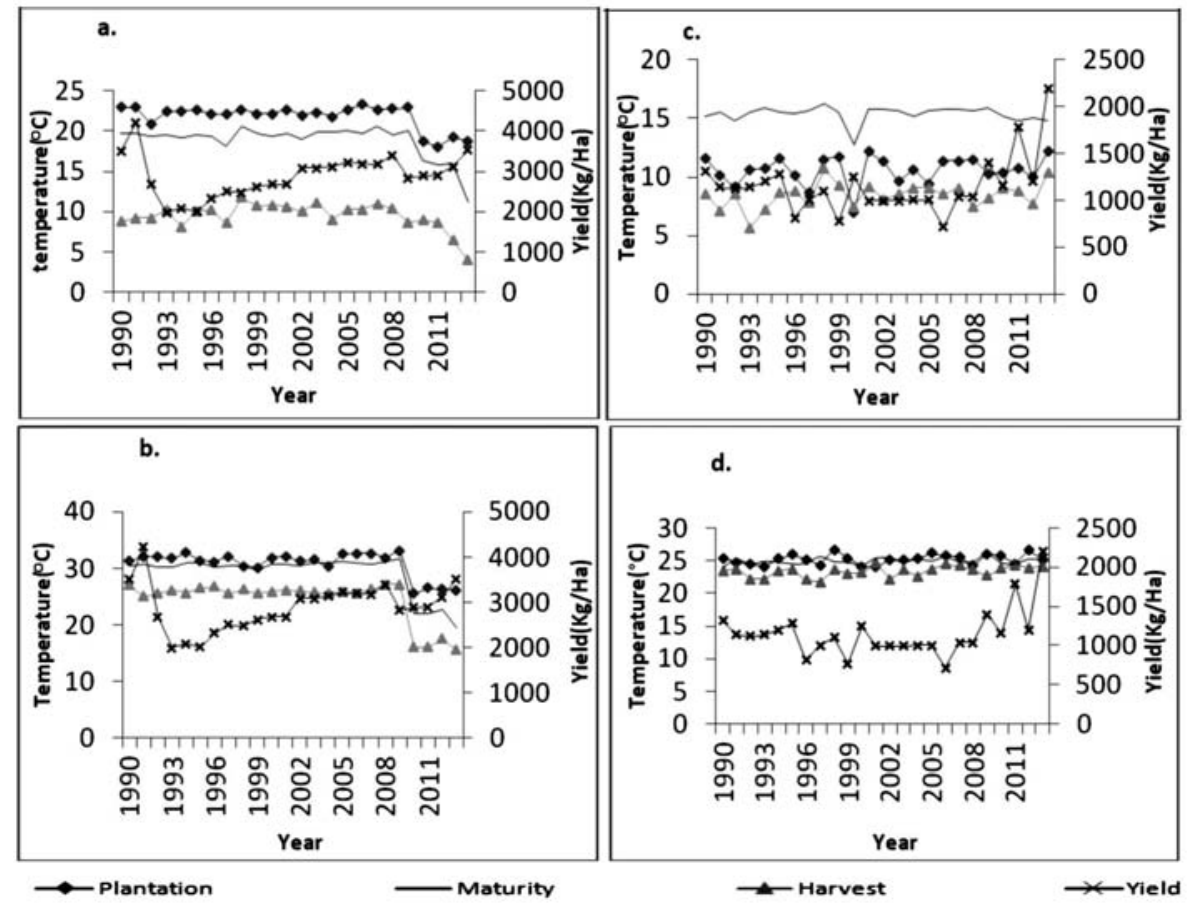

Fig. 2 Relation between temperature and rice yield; minimum temperature (a), maximum temperature and rice yield at Kavre (b), minimum temperature (c), maximum temperature and rice yield at Jumla (d) during different periods
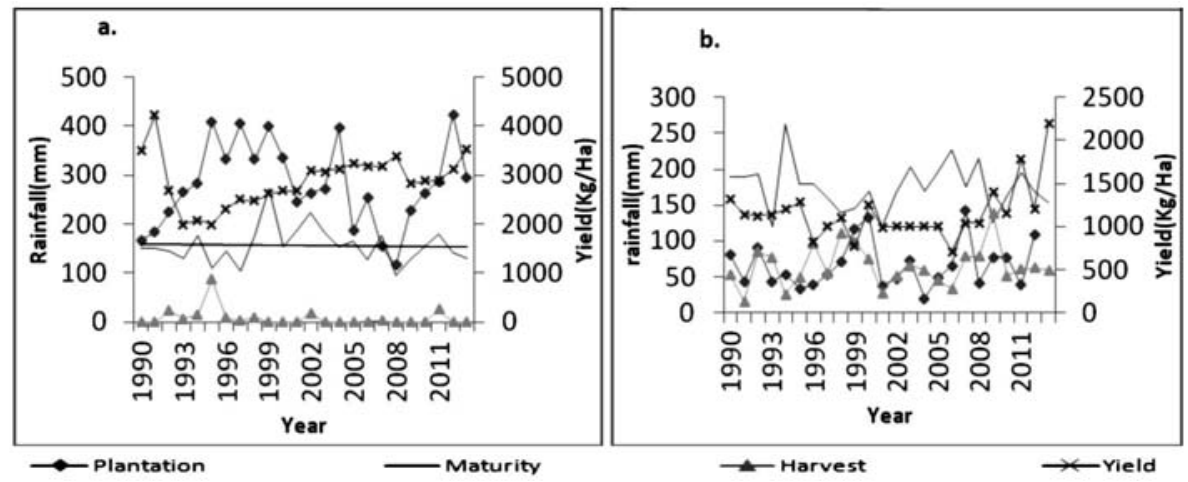

Fig. 3 Relation between total rainfall and rice yield at Kavre (a) and Jumla (b) 
The positive trend of all parameters in harvest period shows the response of climate change positively. It implies that the effect of climate change is more prominent at Jumla which was clearly seen because of lack of irrigation facility, rough soil structure and arid climate. At Kavre, the effect might have minimized because of availability of ir rigation facility, humid climate and assess to chemical fertilizer .
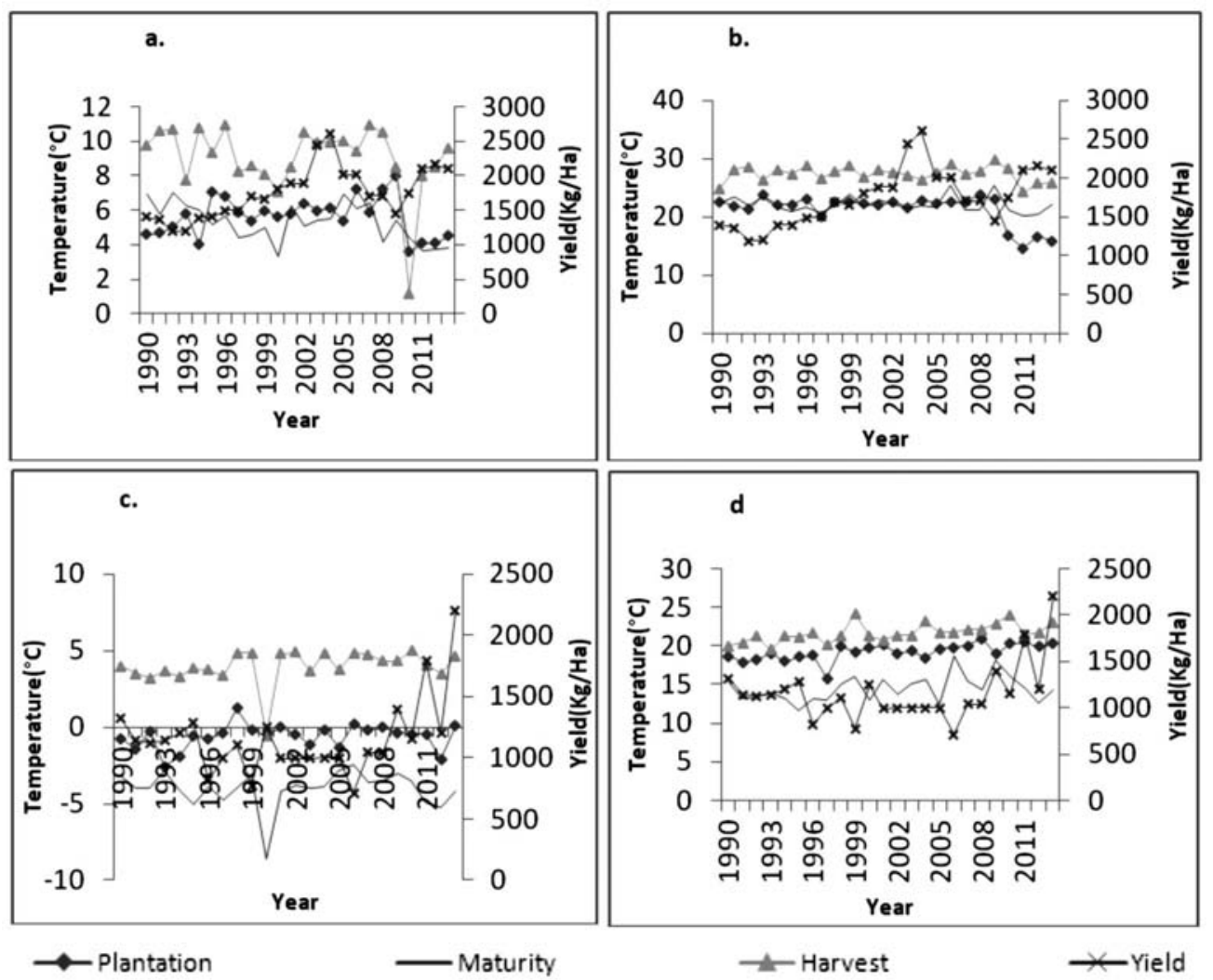

Fig. 4 Relation between temperature and rice yield: minimum temperature (a), maximum temperature and wheat yield at $\mathrm{K}$ avre (b), minimum temperature (c), maximum temperature and wheat yield at Jumla (d) during different periods

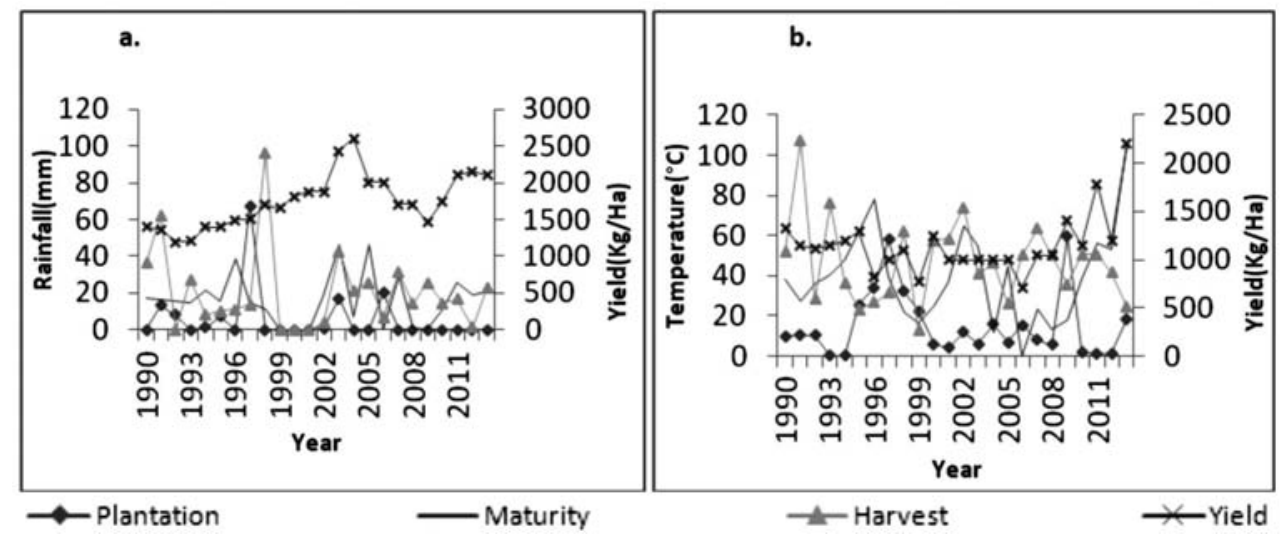

Fig. 5 Relation between total rainfall and wheat yield at Kavre (a) and Jumla (b) 
Table 2. Correlation between temperature and rainfall and rice yield

\begin{tabular}{|c|c|c|c|c|c|c|c|}
\hline \multirow[t]{3}{*}{ S.N } & \multirow[t]{3}{*}{ Parameters } & & \multicolumn{5}{|c|}{ Stations } \\
\hline & & \multicolumn{3}{|c|}{ Kavre } & \multicolumn{3}{|r|}{ Jumla } \\
\hline & & Transplant & Maturity & Harvest & Transplant & Maturity & $\overline{\text { Harvest }}$ \\
\hline 1 & Mean $\mathrm{T}_{\max }$ & 31.76 & 30.76 & 26.05 & 25.21 & 24.93 & 23.32 \\
\hline 2 & $\sigma_{\max }(\mathrm{T})$ & 0.76 & 0.71 & 0.60 & 1.02 & 0.63 & 1.07 \\
\hline 3 & Mean $\mathrm{T}_{\min }$ & 22.46 & 19.59 & 9.73 & 10.57 & 15.54 & 8.43 \\
\hline 4 & $\sigma_{\min }(\mathrm{T})$ & 0.532 & 1.05 & 1.26 & 1.35 & 0.73 & 1.31 \\
\hline 5 & Mean Rainfall & 270.97 & 153.20 & 7.58 & 66.42 & 180.91 & 64.67 \\
\hline 6 & CV of Rainfall & 30.08 & 57.24 & 242.76 & 58.28 & 33.70 & 88.15 \\
\hline 7 & SD of Rainfall & 81.50 & 64.25 & 18.40 & 40.17 & 60.78 & 38.13 \\
\hline 8 & $\mathrm{~T}_{\max }$ corr. with rice yield & 0.045 & 0.027 & -0.31 & -0.162 & -0.176 & 0.044 \\
\hline 9 & $\mathrm{~T}_{\min }$ corr. with rice yield & 0.164 & -0.089 & -0.095 & 0.0659 & 0.024 & 0.206 \\
\hline 10 & Rain corr. with rice Yield & -0.22 & 0.036 & -0.217 & 0.0608 & 0.212 & 0.107 \\
\hline
\end{tabular}

Mean, Standard Deviation (s), Coefficient of Variation (CV), Correlation Coefficient of maximum temperature (Tmax), minimum temperature (Tmin) and rainfall during cropping periods using the data of 1990-2009. The temperature is expressed in oC and rainfall in $\mathrm{mm}$.

Table 3. Correlation between temperature and rainfall and wheat yield

\begin{tabular}{cllllclc}
\hline S.N & Parameters & \multicolumn{7}{c}{ Stations } \\
\hline & & \multicolumn{7}{c}{ Kavre } & Jumla \\
\cline { 3 - 7 } & & Plantation & Maturity & Harvest & Plantation & Maturity & Harvest \\
\hline 1 & Mean $\mathrm{T}_{\max }$ & 22.49 & 22.48 & 27.80 & 19.21 & 14.48 & 21.64 \\
2 & $\sigma_{\max }(\mathrm{T})$ & 0.769 & 1.45 & 1.07 & 1.30 & 2.11 & 1.50 \\
3 & Mean $\mathrm{T}_{\min }$ & 5.78 & 5.33 & 9.27 & -0.60 & -4.02 & 3.97 \\
4 & $\sigma_{\min }(\mathrm{T})$ & 1.032 & 1.335 & 1.215 & 1.16 & 1.41 & 1.37 \\
5 & Mean Rainfall & 5.587 & 15.21 & 19.06 & 15.24 & 39.72 & 46.95 \\
6 & CV of Rainfall & 257.62 & 121.32 & 119.57 & 190.87 & 75.90 & 64 \\
7 & SD of Rainfall & 14.39 & 17.57 & 22.79 & 25.47 & 29.83 & 39.98 \\
8 & $\mathrm{~T}_{\max }$ Corr. with wheat yield & 0.057 & -0.052 & -0.18 & 0.021 & -0.0717 & -.185 \\
9 & $\mathrm{~T}_{\min }$ Corr. with wheat yield & 0.148 & -0.217 & -0.24 & -0.177 & -0.180 & 0.042 \\
10 & Rain corr. with wheat Yield & 0.143 & 0.232 & -0.016 & -0.009 & -0.010 & 0.152 \\
\hline
\end{tabular}

Mean, Standard Deviation (s), Coefficient of Variation (CV), Correlation Coefficient of maximum temperature (Tmax), minimum temperature (Tmin) and rainfall during cropping periods using the data of 1990-2009. The temperature is expressed in oC and rainfall in $\mathrm{mm}$. 


\section{Conclusion}

The growth and development (physiological function) of any crop is gover ned by climatic parameters. The mean annual maximum temperature of Kavre and Jumla showed increasing trend that may account for better prospective of rice production. Increase in maximum temperature at Kavre is not favorable for rice yield, but it is favorable at Jumla. But, decrease in minimum temperature at Kavre is favorable for wheat yield, but it is not favorable at Jumla. The study areas are mountainous with rugged topography. Majority of people are living below poverty line. The main occupation of the household head is agriculture in the both study area. Majority of the land which is considered to be the principal asset is under rain fed condition. Hence, the diversification of crop in limited land for food self-sufficiency is required.

\section{Acknowledgements}

The authors would like to acknowledge District Agriculture Development office at K avre District and Ministr y or Agriculture for providing published and unpublished materials and information related to this study.

\section{References:}

Adams R. M., Rosaenzweig, C., Ritchie.J., Peart, R., Glyer, J., Mc Carl, B.A., Curry, B., and Jones, J. (1990). Global climate change and agriculture: An economic perspective. Nature, 345, 219-224.

Basak, J.K., Ali M.A, Islam, N.M., and Rashid,M.A.(2010). Assessment of the effect of climate change on boro rice production in Bangladesh using DSSAT model. Journal of Civil Engineering, 38 (2), 95-108

Darwin, R., Tsigas, M., Lewandrowski, J., Raneses, A. (1995). World agriculture and climate change: economic adaptations. Agricultural Economic. Report No. 703. Natural Resources and Environmental Division, Economic Research Service, U.S. Department of Agriculture, Washington, DC

DDC-R (2002). District Perspective Plan, District Development Committee, Kavre and Jumla

Decker,W. L.(1994). Management and Analysis of Agroclimate and Agrometeorical Data. Handbook of Agricultural Meteorology. Oxford University Press.

Dixon, B. L., Hollinger, S. E., Garcia, P. \& Tirupattur, V. (1994). Estimating corn yield response models to predict impacts of climate change. J. Agric. Res. Econ.,19, 58-68.

Easterling, W.E. III, Crosson, P.R., Rosenberg, N.J., McKenny, M.S., Katz, L.A., Lemon, K.A. (1993). Agricultural impacts of and responses to climate change in the Missouri-IowaNebraskaKansas (MINK) region. Clim Change, 24, 23-61.
FAO (2004). Compendium of Food and Agriculture Indicators 2004- Nepal retrieved on July 9, 2014, from fao.org/es/compendium 2004/pdf/ESS NEP.pdf

GoN (2011). Climate change policy, 2011, Ministry of Environment, Kathmandu.

IPCC (2014). Climate change 2014: Impact, adaptation and vulnerability. Contribution of working group II to the Fifth Assessment Report of Intergovernmental Panel on Climate Change.

Kaiser, H. M., Riha, S. J., Wilks .D.S., Rossiter D. G., \& Sampath.R. (1993).A farm-level analysis of economic and agronomic impacts of gradual global warming. Am. J. Agric. Econ., 75, 387-398.

Kane. S., Reilly.J., and Tobey.J. (1992). An empirical study of the economic effects of climate change on world agriculture. Clim Change., 21, 17-35.

Karn, P.K. (2014). The Impact of Climate Change on Rice Production in Nepal. SANDEE Working Papers. ISSN 1893-1891; WP 85-14

Kaufmann,R. K. \& Snell, S. E. (1997). A biophysical model of corn yield: integrating climatic and social determinants. Am. J. Agric. Econ., 79, 178-190.

Malla,G.(2008).Climate Change and its Impact on Nepalese Agriculture. The Journal of Agriculture and Environment, 9,64 .

MoAC (2013). Annual Progress Book 2066/67. Department of Agriculture, Ministry of Agriculture and Cooperative, Nepal.

MOPE (2004). Initial National Communication to the conference of the Parties of the United Nations Framework Convention on Climate Change. Singa Durbar, Kathnandu Government of Nepal Ministry of Environment Scienve and Technology.

National Adaptation Programme of Action (NAPA)(2010). Ministry of Environment, Government of Nepal.

Nepal Agricultural Research Council (NARC) (2010). NARC's Strategic Vision for Agricultural Research (2011-2030): Meeting Nepal's Food and Nutrition Security Goals through Nutrition Security Agricultural Science and Technology. Nepal Agricultural Research Council Population and Environment. UNEP, Kathmandu.

Paudel, M.N. \& Thakur, N.S. (2009). Rice (Oryza sativa) in Nepalese agriculture. Hamro Sampada (Nepali), 10, 84-86.

Practical Action. (2009). Temporal and Spatial Variability of Climate Change over Nepal (1976-2005). Practical Action, Kathmandu.

Regmi, B.R., \& Ahikari, A. (2007). Human Development Report 2007/2008-Fighting climate change: Human Solidarity in a Divided World- Country Case Study-Nepal. Human Development Report Office, Occasional Paper no 57. 
Rosenzweig, C., \& Parry, M.L. (1994). Potential impacts of climate change on world food supply. Nature, 13, 133-138.

Sapkota, S., Nath, M.P., Thakur, N.S., Nepali, M.B., \& Neupane, R. (2010). Effect of Climate Change on Rice Production: A Case of Six VDCs in Jumla District. Nepal Journal of Science and Technology, 11, 57-62 57.

Stern, N. (2006). The Economics of Climate Change: The Stern Review. Cambridge, UK Cambridge University Press.
Tao, F., Okozawa, M., Zhang, Z., Hayashi, Y., Grassl, H., \& Fu, C. (2004). Variability in climatology and agricultural production in China in association with the East Asia summer monsoon and El Nino south oscillation. Climate Research, 28, 23-30. 